\section{The Age of Exploration}

T he Renaissance coincided with the great sea voyages and explorations of Columbus, Vasco da Gama, and others. Such explorations necessitated the development of accurate maps and reliable navigational instruments for use at sea.

The Portuguese explorers sailed south and east. Prince Henry the Navigator (1394-1460) sent ships down the west coast of Africa from his palace-observatory, and claimed the island groups of Madeira and the Azores. In 1498 Vasco da Gama sailed around the tip of Africa and reached the west coast of India.

Their rivals, the Spanish, headed west, hoping to reach India by circumnavigating the globe. From 1492 Christopher Columbus (1451-1506), a navigator of genius, led four Spanish expeditions to pioneer a western route to the Indies, but instead they reached the new lands of North and Central America. Further expeditions followed, and "America" was named after Amerigo Vespucci, a Florentine who reached Brazil in 1502.

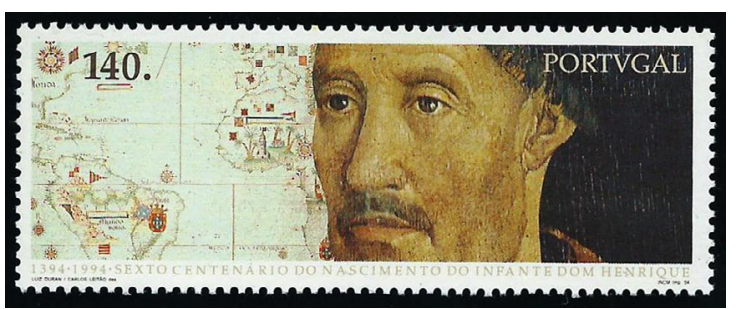

Prince Henry

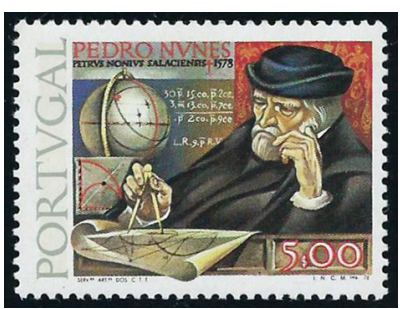

Nunes
These nautical explorations played a major role in the renaissance of map-making, leading to new types of projection and improved maps for navigators at sea, the first to feature America appeared in 1507. Gerard Mercator (15121594) produced his world maps by projecting a sphere onto a vertical cylinder and then stretching the map so that the lines of latitude and longitude appear as straight lines and all compass directions are correct.

One of the first to apply mathematics to cartography was the Portuguese Royal cosmographer Pedro Nunes (15021594), whose 1537 treatise on the sphere showed how to represent "rhumb lines" (the path of a ship on a fixed bearing) as straight lines.

Navigational instruments were used to measure the altitudes of heavenly bodies, such as the sun and pole star, to determine latitude at sea. Astrolabes had calculating devices to take measurements of the heavenly bodies, with a circular scale on the rim and an attached rotating bar to measure altitude. For navigators at sea a sturdy version was developed, known as the mariner's astrolabe

The cross-staff was used for measuring the angular separation between two celestial bodies. Although widely used to measure angles between the sun and the horizon, it required the user to look directly at the sun. The back-staff was a clever modification in which a navigator had his back to the sun.

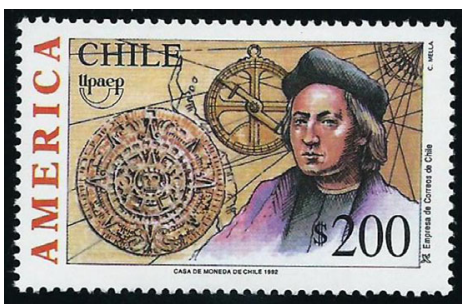

Columbus

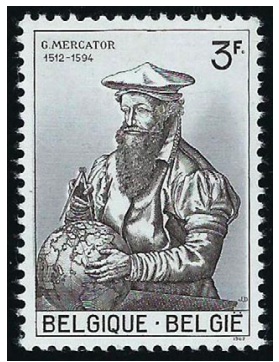

Mercator

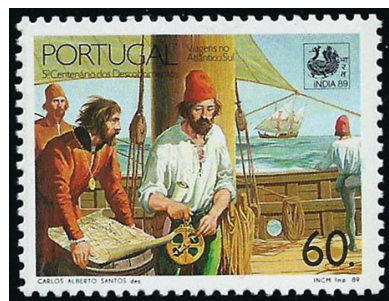

Mariner with astrolabe

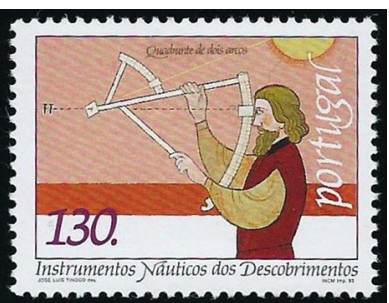

Back-staff

> Column editor's address: Robin Wilson, Pembroke College, 